\title{
The Quality of Geography Learning during Covid-19 Pandemic in Public Senior High School in Bandung
}

\author{
Yanuar Firman Ramadhan ${ }^{1}$, Epon Ningrum ${ }^{2}$, Nandi $^{3}$ \\ \{yafiraa@student.upi.edu ${ }^{1}$, eponningrum@upi.edu ${ }^{2}$, nandi@upi.edu ${ }^{3}$ \}
}

\begin{abstract}
Student, Postgraduate School, Geography Education Program, Indonesian University of Education ${ }^{1}$
Professor, Postgraduate School, Geography Education Program, Indonesian University of Education ${ }^{2}$

Doctor, Postgraduate School, Geography Education Program, Indonesian University of Education ${ }^{3}$
\end{abstract}

\begin{abstract}
This paper aims to describe the quality of geography learning during covid-19 pandemic. In covid-19 pandemic period there was transformation of offline learning to be online. Teacher is not only able to teach offline learning, better if they could teach online and also be adapted by students condition. The reasercher should look at learning plans, learning implementations, and learning outcomes to measure the quality of geography learning. This reasearch used survey methode and statistic presentage. Samples were 8 geography teachers and 94 students 2 th grade at social major in 8 public senior high schools in Bandung. The result are $75 \%$ school have a high quality, and $25 \%$ have a medium quality. In addition, $50 \%$ of the learning outcomes have passed and 50\% still poor. Development of high quality education must be evaluated by educational units indefinitely. Therefore every teachers have to realize and develop their skills.
\end{abstract}

Keywords: Education, Learning Quality, Online Learning.

\section{Introduction}

Learning system in Indonesia is used to have face-to-face meeting between teacher and students. This learning is not only the process of giving knowledge, but also it can be collaborated with the various technologies such as: 1) audio visual, 2) power point, 3) props, 4) printed media, etc [1]. It does not mean offline learing is better than online learning. There needs to be an in depth study of all the participants readiness in do that process. All of the choiches have positive and negative impact for everything. So, it is highly recommmended for the goverment, school, teacher, and parents to always support the govermnet programme or policy especiallly in the education sector[9].

The education transformation has been changed from offline learning into online learning. In the fact, it has created the extraordinary euphoria[8]. Given the accessibility of technology and information on internet, it becomes an opportunity to optimize the learning that has stopped by Pandemic of Covid-19. Online learning makes a great use of technology and information. Students are given the freedom to study the material independently without going to shcool[2]. This 
advantage should be maximazed by students to make online interaction with teacher or their partner to discuss the material without thinking about the location for discussing [4].

However, in the implementation, it has problem especially in geography subject. According to this research about The Immediate of Covid-19 Postsecondary Teaching and Learning (2020) state that[3]:

"Online assessment can help predict final grades, with a statistically significant correlation between online quizzes taken throughout the course and invigilated final examinations in some cases. There's no evidence that students use emergency situations to get special treatment".

Directly, students become an object of the success of learning process that carried out by teacher during Covid-19 Pandemic [3]. The statement is appropriate that teacher are demanded to be able to fulfill the students's needed in optimizing their knowledge [6]. The optimizing of learning objectives is used to make the teacher improve their learning quality. The learning quality is the way to reach the expected learning objectives. On the other hand, the learning quality refers to a good and standardized learning experience [10]. According to this researh about Developed An Anlaysis of Teaching as International Action, state that [7]:

"That a teaching action consisted of three steps: (a) selecting a learning to promote; (b) devising a plan to promote that learning; and (c) implementing that plan".

The statement above become the basic theory of the learning quality. So that, it can be assumed that the learning quality is a learning what is done conscoiusly by pay attention to all inputs, starting from planning according to the context variables, then procecss variable, and the result of learning process. So, that threes assesment will be achived such as knowledge, skills and attitude that is in accordance with the standards [10].

\section{Research Methods}

This research is quantitative with used the descriptive analaysis method. Desscriptive reasearch is is the research method that pointed for describing real phenomena, in the present or in the past ${ }^{[5]}$. In the other hand, this research conducted by means of survey, which is one of collecting information about some phenomena that has been occured in the social area ${ }^{[12]}$. In carrying out the reasearch of the Geography learning quality during Covid-19 pandemic in Public Senior High School in Bandung, there are three steps that will be implemented by reasearcher, such as; (1) planning step, (2) survey step, (3) result and analysis step.

Location of this reaseach is Bandung city where has a good developing process in education. The Bandung Goverment is fully comitted in each aspects of education for both students and teacher can be meet their needs. According to the spasial data dissemination of the list of mayoral regulations about PPDB 2016 for Senior High School level, there are consist of 8 zonation, such as: 


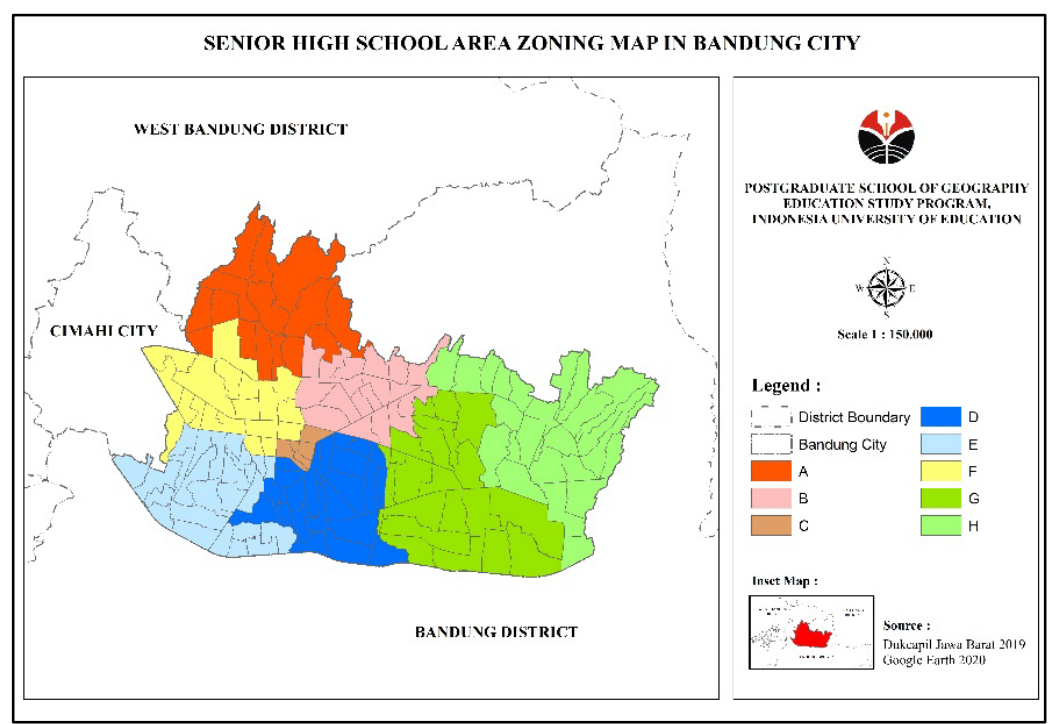

Fig. 1. Senior High School Zoning Map in Bandung.

This reasearch population is according to 8 regional zoning from the whole Public in Senior High School in Bandung. Then, from the whole school, the reasercher determine the student from social major in 2 th grade according to each regional zoning to become an reaserch object. The sample is the geography's teacher and the students. Used the Puropsive sampling technique, which is technique to determine partisipants with some considerations [11]. The following distribution sample of the research:

Table. 1. Distribution of Sample for Each Region Zoning.

\begin{tabular}{cclc}
\hline Area Zoning & Teacher Sample & \multicolumn{1}{c}{ School Name } & Student Sample \\
\hline A & 1 & Bandung 15 SHS & 12 \\
B & 1 & Bandung 10 SHS & 12 \\
C & 1 & Bandung 3 SHS & 12 \\
D & 1 & Bandung 11 SHS & 12 \\
E & 1 & Bandung 4 SHS & 11 \\
F & 1 & Bandung 13 SHS & 11 \\
G & 1 & Bandung 12 SHS & 12 \\
H & 1 & Bandung 23 SHS & 12 \\
\hline
\end{tabular}

Variable in this reaseach is used single variable. Sub variable that has determined is according to content standards and curriculum proses standards in the Regulation of the Minister of Education and Culture No. 22 2016. Every school units in Indonesia should has the learning plan. Implementation learning process, also evaluation of learning process, which is used to develope the efficiency and efectivity achievement of expected sincerity competence. 
Collecting data technique in this reasearch is consist of questionnaire and study documentation. Then, analysis data technique followed by data processing procedures according to approach used. The procedure that used are: (1) checking data, (2) classification data, (3) verivication data, (4) analysis data. Then, the reasearch will be used analysis data for statistic presentage test. The value of the presentage will be interpreted by the research by used average percentage convesion according to determine of the scale range by calculating the number of ideal score in each indicators.

Then, the planning classification of learning and the implementation have score range with divided into maximume score and minimum score. These categories, can be showed in this table:

Table. 2. Classification of Lesson Planning.

\begin{tabular}{cc}
\hline Category & Score Range \\
\hline High Quality & $143-210$ \\
Medium Quality & $79-144$ \\
Poor Quality & $13-78$ \\
\hline
\end{tabular}

Table. 3. Classification of Learning Implementation.

\begin{tabular}{cc}
\hline Category & Score Range \\
\hline High Quality & $432-576$ \\
Medium Quality & $288-431$ \\
Poor Quality & $144-287$ \\
\hline
\end{tabular}

The next activity value will be categorized as assesment of the result recapitulation documents collecting mid test scores and final test scores of the students by the geography's teacher where classify the study completeness according to the average of minimum completeness criteria in the group of Social subject which is 75 . The classification consists of categories, that will show below:

Table. 4. Classification of Learning Outcomes.

\begin{tabular}{cc}
\hline Category & Average Test Score \\
\hline Passed & $>75$ \\
Fair & 75 \\
Poor & $<75$ \\
\hline
\end{tabular}

So, we could see from the table about the learning quality that has given by the geography teacher to the students. According to the result of determination scale range about the geography learning quality, there are obtained the average percatage conversion, it will show below:

Table. 5. Classification of Learning Quality.

\begin{tabular}{cc}
\hline Category & Score Range \\
\hline High Quality & $577-786$ \\
Medium Quality & $367-567$ \\
Poor Quality & $157-366$ \\
\hline
\end{tabular}

\section{Results and Discussion}

\section{Lesson Planning}


According to findings result that has given to 8 geography's teacher, the reasearch has been classified based on score quality of lesson plan (LP), teaching materials (TM), work sheets (WS), learning media (LM), assesment sheets (AS). It will be shown in the figure below:

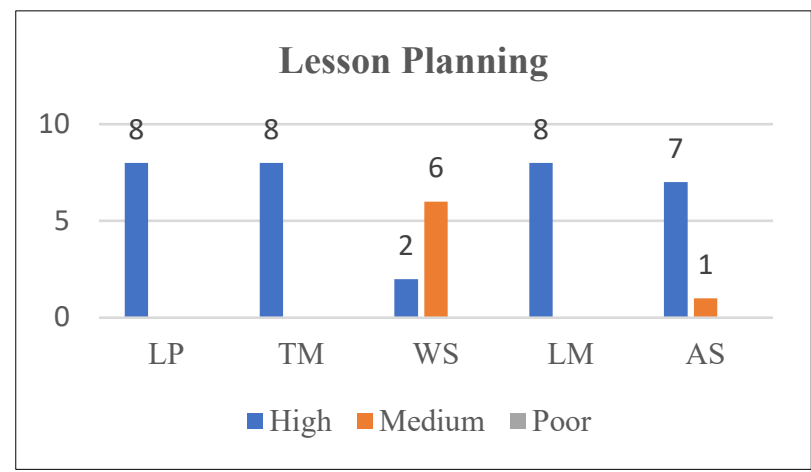

Fig. 2. Lesson Planning.

\section{Learning Implementation}

According to findings result that has given to 8 geography's teacher, the reasearch has been classified based on the score quality of introduction activities (IA), core activities (CA), and closing activities (LA). It will be shown in the figure below:

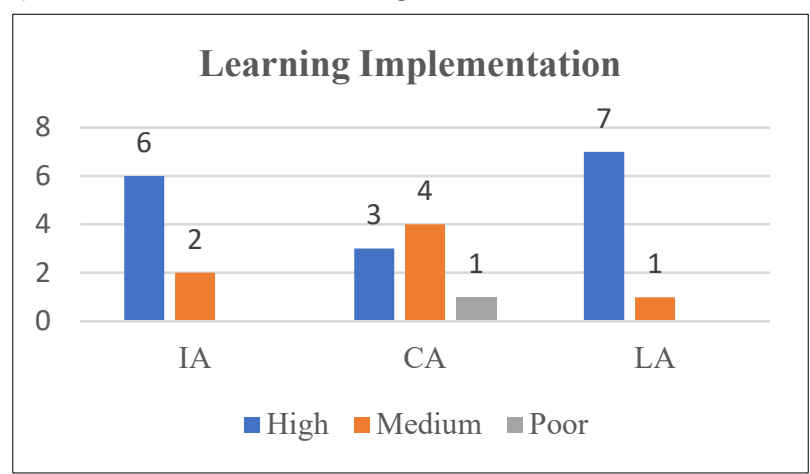

Fig. 3. Learning Implementation.

\section{Learning Outcomes}

According to findings result that has been done to 94 students in $2^{\text {nd }}$ grades Social Major from 8 schools, the reasercher has been classified based on the average scores quality of mid test (MT) and final test (FT). It will be shown in the figure below: 


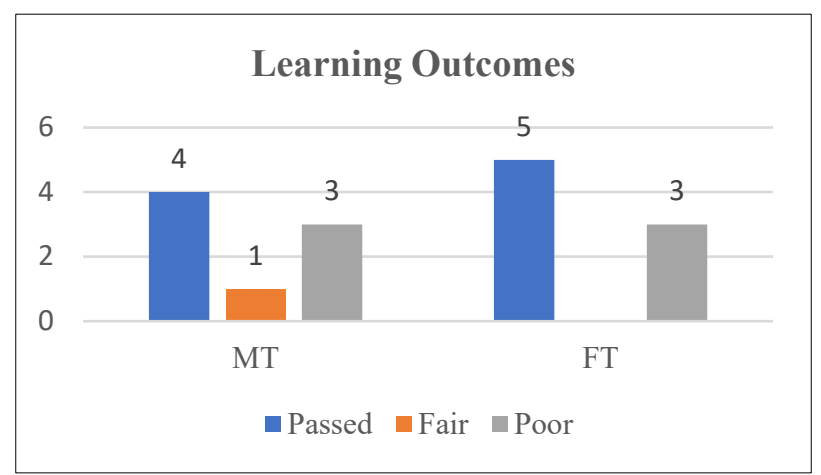

Fig. 4. Learning Outcomes.

\section{Geography Lesson Planning in Public Senior High School in Bandung during Covid-19 Pandemic}

Learning devices planning in this research is used to collect the document of learning devices that has been used by teacher in prepare the learning, after that conducted an assesment based on questionnaire. There are (1) lesson plan, (2) teaching materials, (3) work sheets, (4) learning media, (5) assesment sheets. It will be shown in the figure below:

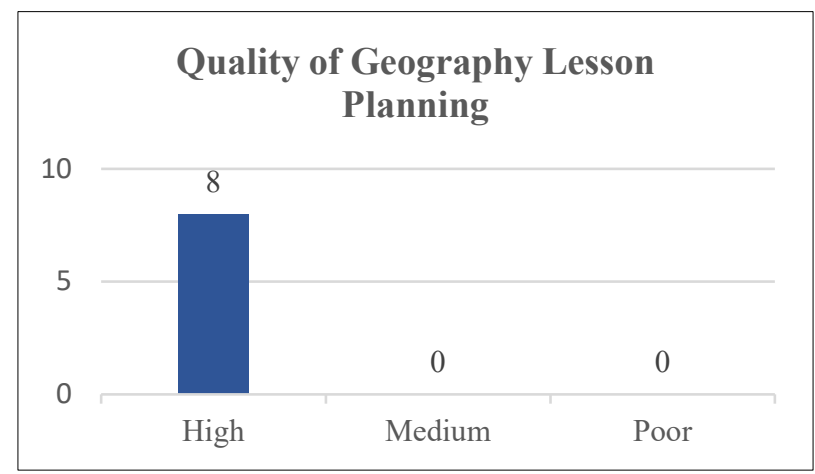

Fig. 5. Quality of Geography Lesson Planning.

Obtained the average score of learning planning from indicators, that has a whole result 185 . It means that learning planning by geogrpahy's teacher in Public Senior High School in Bandung has been made with the best categories. A whole tecaher could make lesson plan especially in Covid-19 Pandemic with a whole by these has been used components and systematic. Teaching Materials are up to standards based on book standards that has been used by education units. The whole teachers are using printed book and online book or e-book. All of the media has been accordance with the students condition, but only one teacher could engage the students for 
implementating the study. Whereas in learning planning, all of the teacher has been accordance the content standards, and the process standards by Permendikbud (2016).

The information of the whole learning devices planning documents by geography's teacher in Public High School Bandung has a high quality. It means that the teacher professionalism in Public Senior High School in Bandung has accomplishments $100 \%$. There are able to make designing of learning devices which is adapted to school and students conditions. Even though, it must be evaluated because the online learning still not finish. It is better to reconsider the learning innovation for online learning. So, the students always be motivated and minimaze the boredom when studying in home without give the same material as the offline study.

\section{Geography Learning Impelmentation in Public Senior High School in Bandung during Covid-19 Pandemic}

The implementation of the learning in this research is doing the questionnaire distribution about implementation of learning that has been implementated by the teacher in achieved the teaching and learning process which is efectively land efficiency. Then, conducted an assesment in each points of quesionnaire such as: (1) introduction activities, (2) core activities, (3) closing activities. It will be shown in the figure below:

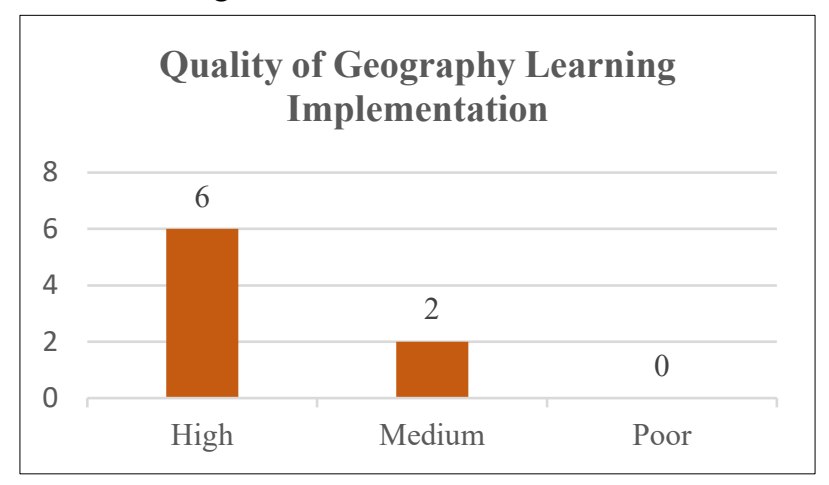

Fig. 6. Quality of Geography Learning Implementation.

Obatined the average of score the geography learning implementation from indicators, and get result 456. It means that learning implementation by geography teacher to students in Public Senior High School in Bandung that has been done with a good categories. There are dominantly geography teacher who has implementated the preliminary activities with sistematic and paying attention to the self readiness and to the students. In addition, half of geography's teacher has been done with core activities. They implementation the $4 \mathrm{C}$ learning and an ideal scientific approachment. The last, there is most of the geography's teacher who has been done with closing activities. They are paying attention to the reflection and evaluation.

The information from the whole sequences of implementation learning activities geography's teacher in Public Senior High School in Bandung is $75 \%$ has a high quality. It means that still needed in a depth about teaching methode in $21^{\text {st }}$ century, as well as the teaching experience to be 
able to adopt opennes from the evaluation in the last year. So, it could be excpected that $25 \%$ teachers who are not optimal in online teaching, they would be always improved their skills and profesionalism. Even though, in Covid-19 Pandemic the process of teaching and learning is doing by online. The Learning still should be developed efectively and eficiency in each school especially in Bandung.

\section{The Student's Learning Outcomes in Geography Subject during Covid-19 Pandemic in Public Senior High School in Bandung}

The learning outcomes in this research is collecting the documents of mid test and final test from the students in geography subject that has been reacpitulated by geogrpahy's teacher. It is for measuring the learning successful. Then, it has been done the classification in each values average from the Senior High School students, it will be shown in the figure below:

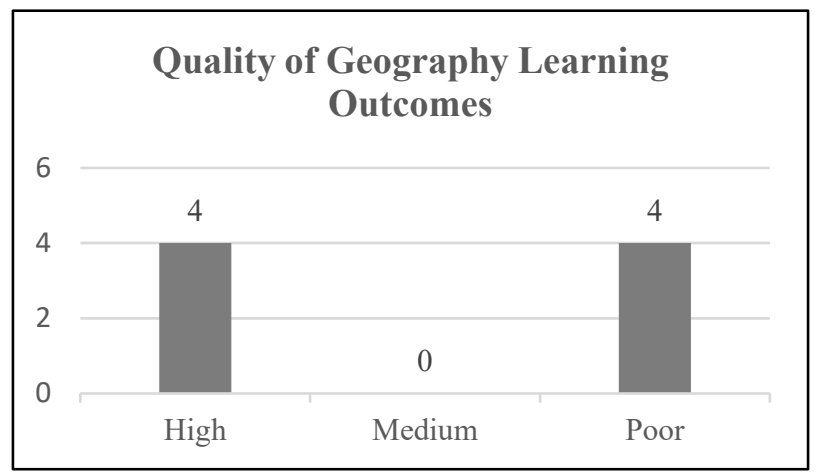

Fig. 7. Quality of Geography Learning Outcomes.

Obtained the average grades of each students which is: the evaluation of mid test and final test, it has average grades is 76 . It means that the evaluation of geography in the cognitive realm from the students in Public Senior High School in Bandung has been obtained the score in a good categories. In addition, obtained the avergae grades of mid test and final test which is down. Previously, the result of mid test that has been known has average score is 78 , than the average score for final test is 74 . So, this indicates a decreasing grade by students has been lost for 4 digits. The result has directly proportional to the condition of Covid-19 Pandemic. Whereas the students still have feeling more obstacles in the online learning. The whole information from the learning result of geography subject in Public Senior High School in Bandung has 50\% passed and remaining $50 \%$ of it has poor. It means that the teacher profesionalism should be improved especially in the teaching process. So, it will be excpected half of students who is not optimized in learning will improve their ability by the teacher. In addition, the mid test and final test grades that has been decreased should be evaluated for next year. The teacher could minimize a decreasing grade or they will be able to improve student learning outcomes, particularly in geography subject. 


\section{Conclusion}

Learning plans and Learning implementations is one of the unity in measuring the learning quality that has been given to the students. When combining both of quality and integrity, every teachers is expected to not only give the study, but also they can improve their teaching ability and their skill. It means that the $21^{\text {st }}$ century teachers should have increase and improve their knowledge in this millenial era. In this reasearch is obtained the information of the $75 \%$ geography's teacher in Public Senior High School has a high teaching quality. While $25 \%$ has a medium quality of teaching.

Geography study is the result of their final achievement in learning quality based on their grade average. Where the students learning outcomes is reflected to the teacher in their successful teaching process. Characterized by their attitude changes, such as cognitive aspect, psychomotor, and affective. The changing process could be occured from the simple thing into complex. This reasearch is obtained the information about $50 \%$ of the learning outcomes has passed. While the remaining $50 \%$ of the learning outcomes has a poor. The development of learning still have to evaluated by educational units. So that, the every teacher should realize and would like to improve their skills to reminder that they have the important position in the learning quality.

\section{References}

[1] Anggrawan, Azhar, Triwijoyo, Mayadi. Descriptive Analysis of Face-to-Face Learning and Online Learning Learning Outcomes According to Student Learning Styles. MATRIK. 2019; 20 (2) : 427-434.

[2] Busthomy dan Hamid. Learning Readiness of Students Against Online-Based Islamic Religious Education (IRE) Learning Outcomes During the Covid-19 Pandemic At SMK Antarctica 2 Sidoarjo. HIKMAH. 2020; 9 (1) : 1-14.

[3] Day, Chang, Chung, Doolittle, Housel, McDaniel. The Immediate Impact of Covid-19 on Postsecondary Teaching and Learning. Taylor \& Francis. 2020; 73 (1) : 1-13.

[4] Gunawan, Suranti, Fathoroni. Variations Of Models And Learning Platforms For Perspective Teachers During The Covid-19 Pandemic Period. IJTE. 2020; 1 (2) : 61-70.

[5] Hamdi dan Bahruddin. Quantitative Applications In Education. Yogyakarta: DeePublish; 2014. 5-6

[6] Herliandry, Nurhasanah, Suban, Kuswanto. Lessons Learned During the Covid-19 Pandemic. JTP. 2020; 22 (1) : 65-70.

[7] Kerr. The structure of quality in teaching. In J. F. Soltis (Ed). Philosophy and Education. 1981. 1 : 6193.

[8] Pangondian, Santosa, dan Nugroho. Innovation and Utilization of Online Learning Technology in the Industrial Revolution Era 4.0. Medan: SAINTEKS. 2019; 9, Factors Affecting the Success of Online Learning in the 4.0 Industrial Revolution; 56-60.

[9] Pentina dan Neeley. Differences in Characteristics of Online versus Traditional Students. Taylor \& Francis. 2007; 17 (1) ; 49-65.

[10] Setyosari. Creating Effective and Quality Learning. JINOTEP. 2014; 1 (1) : 20-30.

[11] Trisnani. Sampling and Survey Engineering Module. Wates: Teacher Education and Elementary School; 2019. 25-30.

[12] Yuliansyah. Increasing Response Rate In Survey Research (Literature Study). South Jakarta: SMART; 2016. 12-16. 